\title{
Job Satisfaction of Teachers: A Comparison Between Day School and Boarding School Under Wangdue Dzongkhag
}

\author{
Pema Sherpa ${ }^{1 *}$ and Thinley ${ }^{2}$ \\ ${ }^{1}$ Dorokha LSS, Samtse, MoE, Bhutan \\ ${ }^{2}$ Mindruling Primary School, Samtse, Bhutan \\ *Corresponding Author: Pema Sherpa, Dorokha LSS, Samtse, Bhutan. Email: sher- \\ paco@education.gov.bt
}

Received: September 28, 2021

Published: October 07, 2021

(C) All rights are reserved by Pema Sherpa and Thinley.

\begin{abstract}
Job satisfaction in any service is difficult to weigh as it depends on numerous factors. At some point it is too sensitive and varies between the individual. Teaching as a profession has its own strength and weakness. Of late Bhutanese teacher started to complain on their responsibilities being too heavy and tiresome. The rate of teacher quitting from the profession showed that teachers are not satisfied with their job. The teachers also felt that there lies difference in work burden between day school and boarding. Teachers agreed that boarding school needs some incentives for the extra responsibilities which the Ministry of Education is not aware of. It is due to the fact that there is no research conducted to understand and resolve the issue.
\end{abstract}

This research has collected the views from 26 teachers from Primary to Higher Secondary School within Wangdue District. The respondents were from boarding and day school. The respondent's age ranged from 30 - 50 years who served as a teacher ranging from 1 - 30 years in different level of school. The very purpose of carrying out research was to find out the level of job satisfaction between day and boarding school teachers.

The research was based on quantitative method since it is small scale for academic purpose and objective oriented. Stratified random sampling method was adopted for collecting data. This method was used as it requires smaller sample which provides best representation from the sample population. The research took three variables (Heavy teaching periods, Other responsibilities and need satisfaction) to find out the relationship between day and boarding school teachers on job satisfaction. The data were analyzed by using SPSS and MS excel.

The result from first variable shows that $77 \%$ of teachers are tired of heavy teaching periods and $92.3 \%$ mentioned that they couldn't focus on quality teaching. Similarly $61.6 \%$ felt that substitution class is another burden. These all has greatly affected the teacher leading to low level of job satisfaction.

The second variable other responsibilities assigned by the school also showed low level of job satisfaction. Teacher's work do not end within the four walls of the class. So they need to work extra hours but were not paid for working more (92.3\%). In the same line $100 \%$ of the respondent opined that boarding school teacher has extra responsibilities but never incentivized to up lift their consistency in their work. Thus data depicts lower satisfaction for boarding school teacher than day school teacher.

Teacher felt that their need was not satisfied as per their expectation. Government holidays (61.6\%) and Sundays (76.9\%) are almost utilized as normal working hours which affected their private time (71.2\%). Moreover boarding teacher felt greater burden due to extra responsibilities.

The study concludes that heavy teaching periods, other responsibilities and needs has strong relationship in determining the job satisfaction of teachers between day and boarding schools. The research has also suggested some recommendation to increase the job satisfaction of teachers by the Ministry of Education.

Keywords: Teaching Period; Responsibilities; Satisfaction; Workload 


\section{Introduction}

This research is designed to study the main reasons behind job satisfaction level of teachers in boarding school versus day school (Boarding school is defined as schools where student stay in the school throughout the year except summer and winter break. They are provided with food and hostel facilities almost similar to their home. After the class hours they are taken care by caretaker called as warden/matron and by the school authority. Their day activity begins as early as 4:30AM and ends at 9:00PM. Teachers monitors study hours on rotational basis. Day school is defined as a school where student attend school during instructional hours and returns to their home in the evening. Often they were provided with day meal. They also take part in other school activities with boarding students.). The interest on this topic is because teachers started to compare the responsibilities between day school and boarding school. It has not been national issue at this juncture but it is certain in near future. This research proposal is divided in to five parts. The first part discusses the problem statement, which comprises of the research problem, background to the study, the main purpose of the research problem, and the research questions and objectives. The Second part discusses on literature review along with the theoretical framework of the dependent and independent variables. The third part discusses about the research design, which also includes the sample design and reason for choosing the method. The fourth part mentions the delimitation or boundaries of the proposed research, the data collection, analysis techniques, limitations and result of research. Lastly, fifth part includes a conclusion, recommendation, references and appendices.

\section{Materials and Methods}

This research was intended to find out the job satisfaction of teachers in boarding school and day school. The research has adopted quantitative method. The data collection was done by using stratified random sampling method through printed questionnaires. The respondents were identified and informed about the research project to be carried out through the head of school. All the respondents were from four schools identified as target population. The survey questionnaires was self-administered to get reliable responses from the respondents.

\section{Results and Discussion}

Results and discussion must illustrate and interpret the reliable results of the study.

As per the sample, data were collected from 26 respondents from four different schools. Respondents were randomly selected through the head of the institution keeping the equal ratio of male and female as shown in table 1 . The age of respondent ranges from 30 years to 50 years old.

\begin{tabular}{|c|c|c|c|c|}
\hline \multicolumn{2}{|c|}{} & Frequency & Percent & Valid Percent \\
\hline \multirow{3}{*}{ Valid } & Male & 13 & 50.0 & 50.0 \\
\cline { 2 - 5 } & Female & 13 & 50.0 & 50.0 \\
\cline { 2 - 5 } & Total & 26 & 100.0 & 100.0 \\
\hline
\end{tabular}

Table 1: Gender frequency.

The age frequency pie chart (Figure 1) below shows that there were 61.54 respondents in the age group of $41-50$ years, $34.62 \%$ in $31-40$ years and $3.85 \%$ in the age group of $20-30$ years.

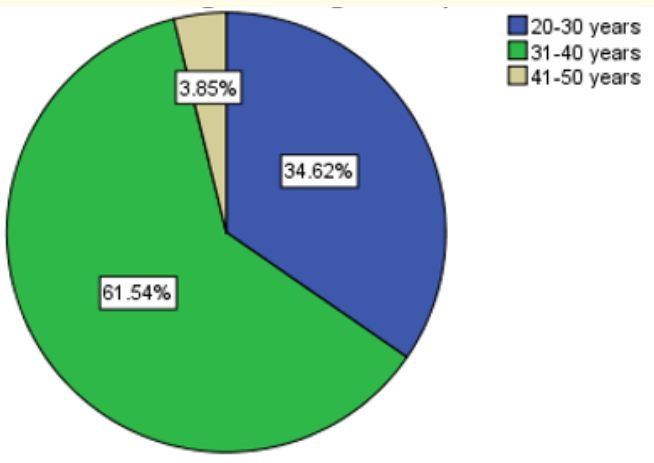

Figure 1: Age group.

\section{Location}

The schools identified for survey are located in semi-urban part of the same district. Two of the sample school provides boarding facilities where almost all the facilities are given by the government and other two school functions as a day school. Although all the sample schools are located in semi-urban zones of the district, they have different culture and physical ambiance. The school that provides with hostel facilities are located away from core town which accommodate students from far flung places. Both students and teachers prefer to work and study in day schools which are located in core town as it provides better facilities.

\section{Impact of heavy teaching periods on job satisfaction}

The first variable, heavy teaching period consists of ten statement for respondent to respond from strongly disagree to strongly agree. These statement will find the connection between 
the heavy teaching period and job satisfaction. The survey was conducted in both day and boarding school teachers. About $77 \%$ ( 20 of $\mathrm{N}=26$ ) opinioned that they are tired of heavy teaching period (Figure 2) upon considering both the scale of somewhat agree and strongly agree (Appendix 2). Although $50 \%$ of teachers mentioned that substituted class is burden for them yet school authority has not explored incentives (61.6\%) for the same as shown by data (Appendix 2). Unlike Finnish education, low quality of Bhutanese education may be attributed to heavy teaching periods where $92.3 \%$ ( 24 of $\mathrm{N}=26$ ) of the respondents opinioned that they could not focus on quality teaching (Appendix 2). Thus the above stated reasons clearly indicates that teachers are not satisfied in their job due to heavy teaching periods.

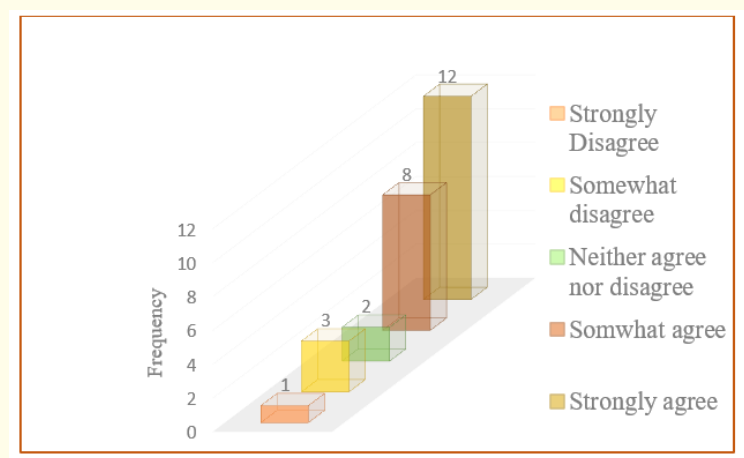

Figure 2: Tired with numbers of teaching period.

\section{Impact of other responsibilities}

The second variable intended to find out the relationship between other responsibilities assigned by the school and the job satisfaction of teachers. On considering two scale of somewhat disagree and strongly disagree, of 26 respondents, 24 or $92.3 \%$ mentioned that working longer hours in the school has no motivation owing to lack of incentives (Figure 3). Similarly 100\% respondents opinioned that boarding school has extra responsibilities as compared to day school which has to be incentivized to attract teacher in boarding school (Figure 3). This indicates that the stress and workload is felt greater in the boarding school as compared to day school which is in line with the findings of Dorji 2009 [1] and Tashi 2014 [2] on workload and occupational stress respectively.

\section{Impact of need satisfaction}

Satisfaction in terms of needs is third variable which relates with job satisfaction of teachers like any other civil servant. Leisure

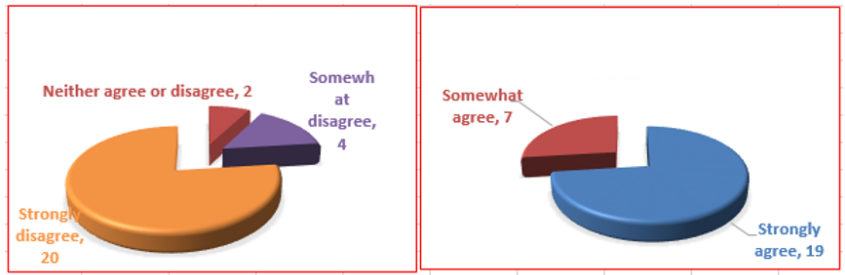

(a)

(b)

Figure 3: (a). School provides me with an incentives for working longer hours. (b). Boarding school teachers has extra responsibilities than day school teacher.

time, off from work during government holidays, higher wages for sacrificing time and energy were identified as a tools for enhancing job satisfaction. As indicated by the data below (Table 2) teachers were working even during government holidays (61.6\%) as usual (appendix 2). However the findings from above two variables shows that they were not motivated through any means to meet their ends. In same line the data also depicted (71.2\%) that they hardly get quality time to spend with their family, parents and friends (Appendix 2). Similarly result also outlined that 20 of $N=26$ opined that they have to work during Sundays while 50\% (Appendix 2) of the teachers has debts in different financial institution showing that the salary they receive are not sufficient to fulfill their needs. So in a nut shell Bhutanese teachers are not satisfied in their job due to low level of salary, benefits and potential rewards (Saiti and Papadopoulos, 2015) [3].

\begin{tabular}{|c|c|c|c|c|}
\hline \multicolumn{2}{|c|}{} & Frequency & Percent & $\begin{array}{c}\text { Valid } \\
\text { Percent }\end{array}$ \\
\hline \multirow{4}{*}{ Valid } & Somewhat disagree & 3 & 11.5 & 11.5 \\
\cline { 2 - 5 } & Neither agree nor disagree & 7 & 26.9 & 26.9 \\
\cline { 2 - 5 } & Somewhat agree & 8 & 30.8 & 30.8 \\
\cline { 2 - 5 } & Strongly agree & 8 & 30.8 & 30.8 \\
\cline { 2 - 5 } & Total & 26 & 100.0 & 100.0 \\
\hline
\end{tabular}

Table 2: Most of the time I work as usual during government holidays.

\section{Testing hypothesis using descriptive statistics}

Descriptive statistics are the summary of data in the form of frequency tables, pie charts and bar charts. Descriptive hypothesis 
are very much useful for testing statistical significance. It encourages researchers to concretize the existence of relationship between two variables. Besides that it helps to think about the implication of void hypothesis and significant hypothesis.

\section{Hypothesis 1}

There exist no significant differences in job satisfaction of teachers in relation to heavy teaching periods between day school and boarding school in Wangdue dzongkhag.

The day school and boarding school teacher's data (Figure 4) revealed that teachers are tired of having higher number of teaching period. It was also found out that the other responsibilities exhibited further burden to teaching (Figure 5).

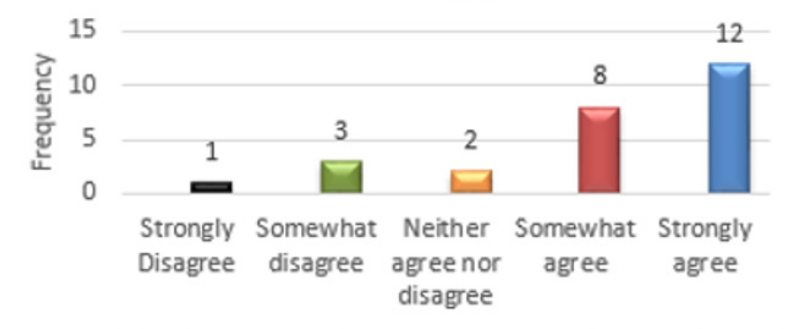

Figure 4: I am tired with numbers of teaching period.

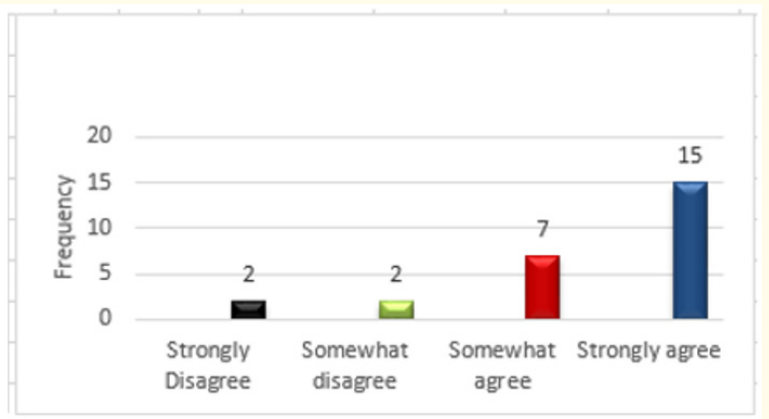

Figure 5: Other responsibilities in the also contributes tiredness in teaching.
While considering the strongly disagree and somewhat disagree scale 16 out of 26 respondents also opinioned that they are equally loaded with other responsibilities along with higher number of periods (Figure 6). The data (Figure 7) displayed that 21 out of 26 respondents agreed to higher burden of teaching in boarding school than in day school. Thus hypothesis is rejected. So in a nut shell it signifies that teaching burden is due to higher number of periods and other heavy responsibilities. As a result teachers are not satisfied in their job in general. The data equally presents that boarding teachers bears greater burden in terms of teaching resulting in lower level of satisfaction in their job.

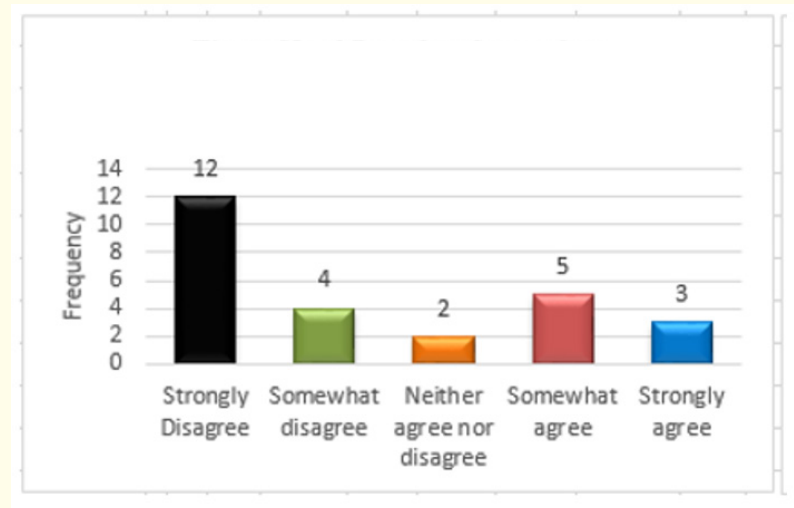

Figure 6: I am free from other responsibilities due to higher instructional period.

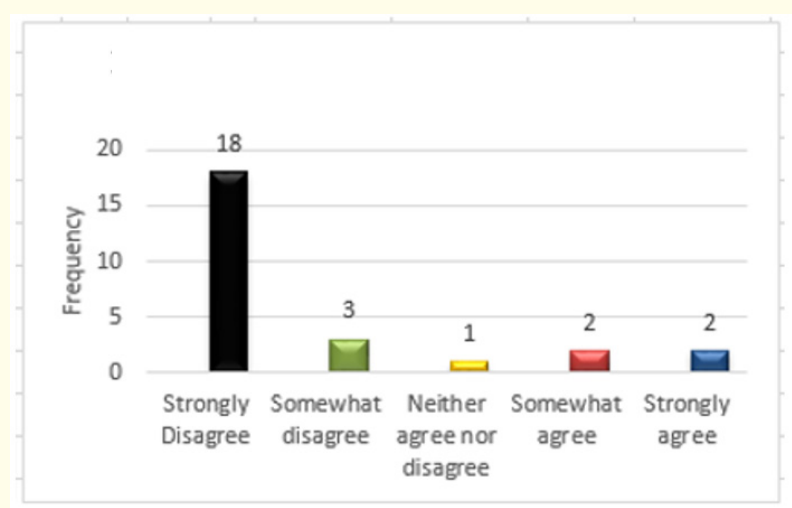

Figure 7: Burden of teaching is same in day school and boarding school. 


\section{Hypothesis 2}

There exist no significant difference in job satisfaction of teachers in relation to other responsibilities between day and boarding school teacher.

It is well known facts that boarding school has greater responsibilities as compared to day school. It is also supported by the data collected from 26 respondents of day and boarding school. Both day and boarding teachers agrees that boarding school has more disciplinary issues which often lead to work extra hours to resolve it (Figure 8). Equally important that none disagreed (100\%) that boarding school has extra responsibilities (Figure 9). So the hypothesis is void.

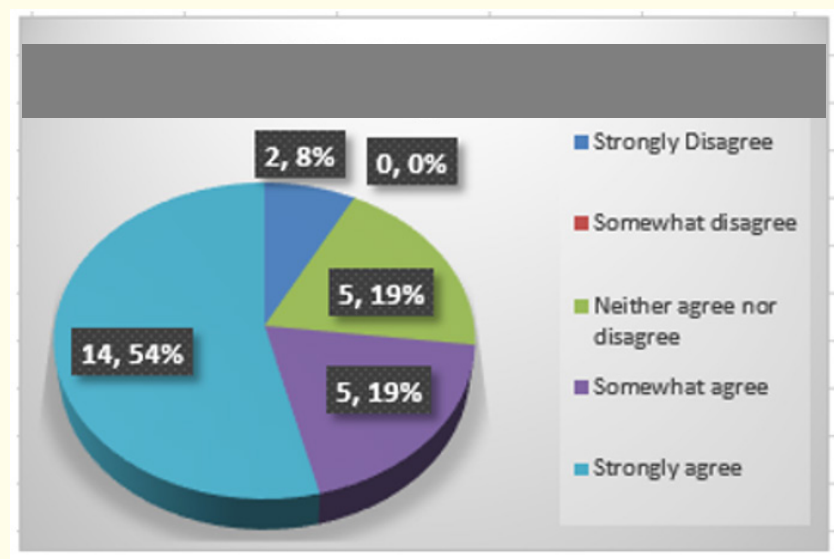

Figure 8: Disciplinary issues are more in boarding school.

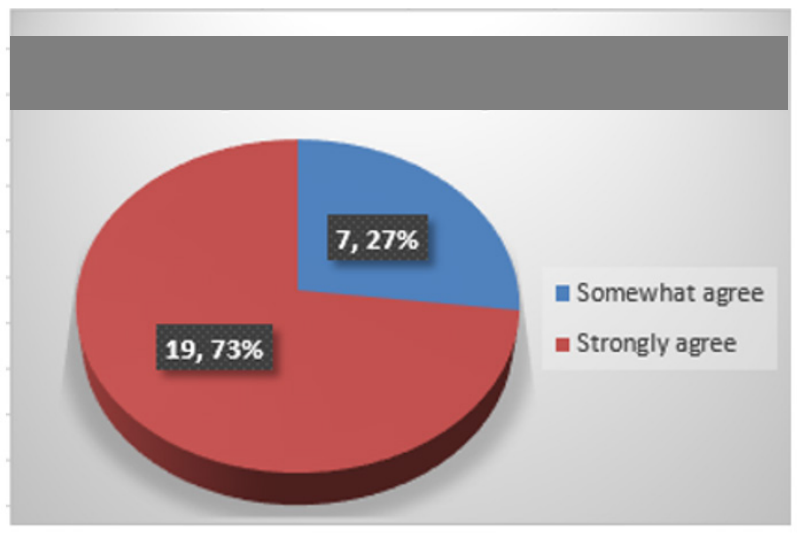

Figure 9: Boarding school teachers has extra responsibilities than day school teacher.
In same context, both the school felt that they would be glad if their non-academic activities are carried out by the support staff (Figure 10) since working longer hours has no incentives (Figure 11).

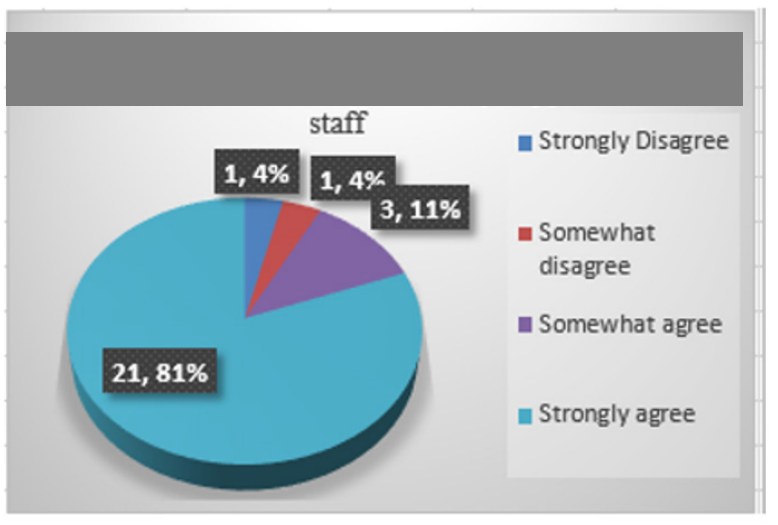

Figure 10: I would be happy if non-academic activities were taken by support staff.

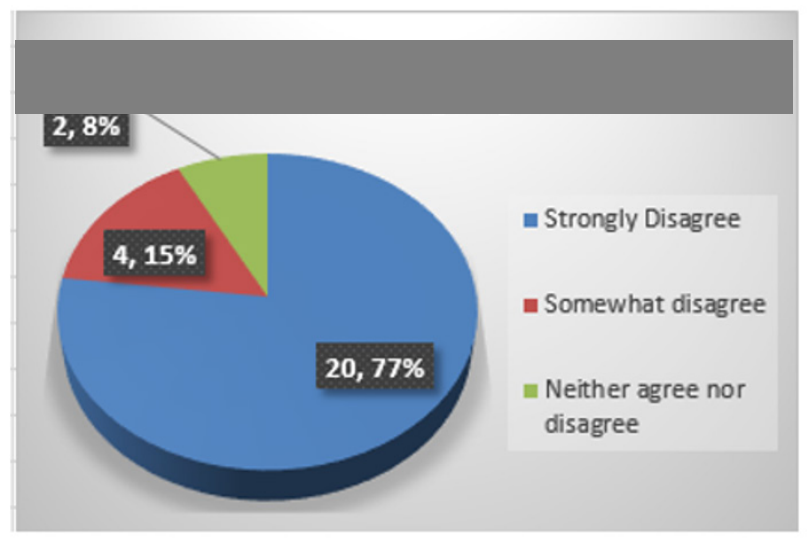

Figure 11: School provides me with incentives for working longer hours.

This strongly shows that there is strong relationship between the level of job satisfaction with in Bhutanese education system. Day school teacher has less work burden than boarding school teacher with same incentives. Thus boarding school has grievances on job satisfaction. 


\section{Hypothesis 3}

There exists no significant relation in job satisfaction of teachers in relation to the need satisfaction between day and boarding school teachers.

The time during the weekends and national holidays are much awaited by any civil servant. These time were used fruitfully for different purposes. But it is not uncommon for teachers that they need to work as usual even during weekends and government holydays. The figure 12 , showed that 16 out of 26 opinioned that they work as usual during government holidays while figure 13 , showed that 20 out of 26 respondents said that Sunday is a normal working day. So in general teachers weren't happy in their service. The main cause for teachers to work even during holidays is that they need to celebrate the day and engage the student. Boarding school teacher becomes even busier as they need to engage boarding students during weekends.

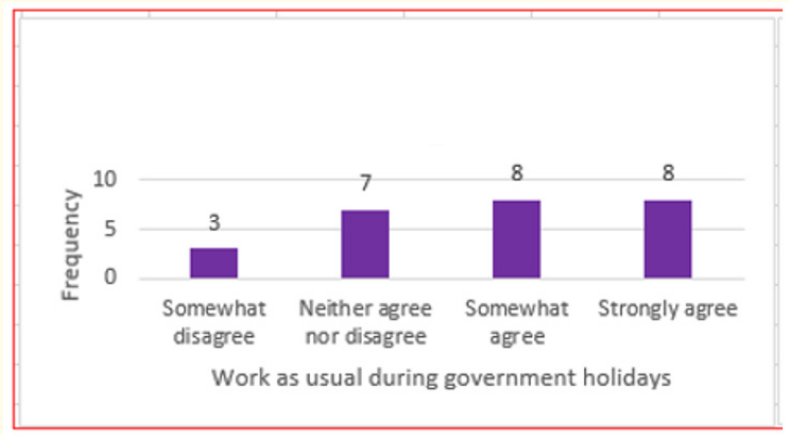

Figure 12: Most of the time I work as usual in the school during government holidays.

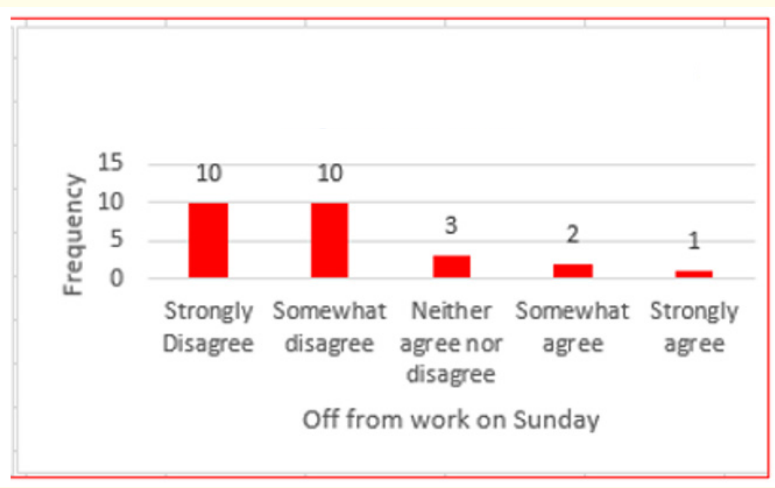

Figure 13: I relax on Sunday without any school work.
Since teacher work even during government holidays and weekends they deserve some incentives which is not there in the system as of now. Figure 14 clearly states that boarding school teacher require some incentives as they work more than day school teacher. Thus above all, it shows that teachers are not satisfied in their job and most importantly boarding school teachers not as satisfied as day school teachers since their needs were not met. Therefore the hypothesis is insignificant as there is strong relation between the day and boarder school teacher in terms of meeting their needs [4-14].

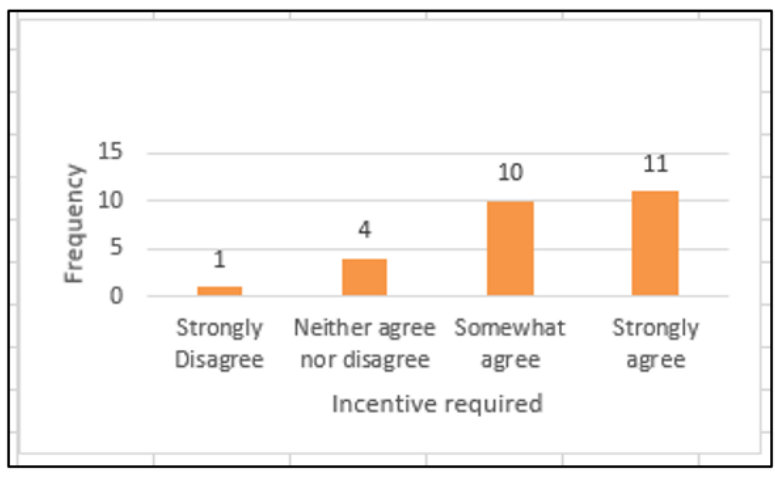

Figure 14: Boarding school need some incentive besides salary.

\section{Conclusion}

According to the findings of the research, the following recommendation are suggested to improve job satisfaction level of teachers:

- Ministry should employ more teacher to reduce teaching burden which will bring quality in Bhutanese education system. Ultimately it will ease the work of teacher and uplift their motivation in teaching profession.

- Ministry should explore to deploy more support staff to reduce the burden of non-academic activities. This will help teacher to perform better in academic due to decreased burden in other responsibilities.

- Ministry must focus Sunday as a compulsory off day for both teachers and student as it is the only day for cleaning and washing.

- Ministry of education should incentivize boarding school teachers as they have more responsibilities than day school.

- Ministry should conduct similar type of research at the national level to validate and provide necessary intervention. 
- This research has attempted to find out the satisfaction of job between the teachers of day and boarding schools of Wangdue Dzongkhag. Three independent variables were used to correlate with the dependent variable. Stratified random sampling method was used for data collection and were analyzed by using SPSS and Microsoft Excel. Through this research, some recommendation were drawn to draw the attention of Ministry of education for support and intervention as well.

\section{Acknowledgements}

I would like to thank 26 teachers of Samtengang Central School, Bajo Higher Secondary School, Nobding Lower Secondary School and Wangdue Primary School of Wangdue District for sharing their opinion enthusiastically for the research.

My thanks also goes to Mr. Thinley Dorji, Education Monitoring Officer for spearing time to teach basics of SPSS. Finally, my sincere thanks also goes to my course mates, Mr. Chrysolyte Choragudi, Mr. Kuenzang Wangchuk, Mr. Sangay Tshering, Mr. Trashi Dorji, and Mr. Samten for necessary support rendered.

\section{Conflict of Interest}

No conflict of interest.

\section{Bibliography}

1. Karma Ura and Dorji Penjore. "Bhutan Health Care Reform: A Paradigm Shift in Health Care to Increase GNH". Dorji, Chencho. [ed.]. Thimphu: Centre for Bhutan Stuides. Gross National Happiness Practice and Measurement (2009): 413-435.

2. Tashi K. "Occupational Stress Among Bhutanese Teachers". Department of Education, Chosun University, Asian Journal of Management Sciences and Education (2014): 3.

3. Saiti Anna and Papadopoulos, Yiannis. "School Teachers' Job Satisfaction and Personal Characteristics". International Journal of Education Management 29 (2015): 18-43.

4. Adetunde AI and Asare B. "Comparative Performance of Day And Boarding Students In Secondary School Certificate Mathematics Examinations". Department Of Mathematics, Faculty Of Engineering, University Of Mines And Technology, Tarkwa. Ghana (2009).

5. Akiba GLM. "Characteristics of teacher incentive pay programs: a statewide district survey". Journal of Educational Administration 53.6 (2015): 702-717.
6. Butt G and Lance A. "Secondary Teacher Workload and Job Satisfaction: Do Successful Strategies for Change Exist?" Educational Management Administration and Leadership 33.4 (2005): 401-422.

7. Collie R J., et al. "School Climate and Social-Emotional Learning: Predicting Teacher Stress, Job Satisfaction, and Teaching Efficacy The University of British Columbia". Journal of Educational Psychology 104.4 (2012): 1189-1204.

8. Lam B and Yan H. "Beginning teachers' job satisfaction: the impact of school-based factors". Teacher Development: An International Journal of Teachers' Professional Development 15.3 (2011): 333-348.

9. Nyatanga E K and Daniel Ndudzo D. "Disparities in Performance in Mathematics between Boarding and Non Boarding Schools: A Study of the Seven Districts of Manicaland Province, Zimbabwe". IOSR Journal of Business and Management (IOSR-JBM) 17.15 (2015).

10. Ololube N P. "Teachers Job Satisfaction and Motivation for School Effectiveness: An Assessment". University of Helsinki Finland (2007).

11. Saleh S., et al. "A study of students' achievement in algebra: Considering the effect of gender and types of schools". University Sains Malaysia. MALAYSIA. European Journal of STEM Education 1.1 (2016): 19-26.

12. Violet N O. Comparative study of the reading habit of day and boarding secondary school students in the Federal Capital Territory Department of Policy and Implementation, FCT Ministry of Education, Abuja, Nigeria (2014).

13. Tshering P. “No School on Saturday (blogpost)” (2016).

14. Porter and Lawler (2014-2016) Organizational Behavior, Model of Motivation.

Volume 4 Issue 11 November 2021

(C) All rights are reserved by Pema Sherpa and Thinley. 